\title{
PEMBERIAN KOMPRES PLESTER HANGAT DAN AROMATERAPI TERHADAP DYSMENORHEA REMAJA PUTERI
}

\section{GIVING WARM AND AROMATHERAPY PLESTER COMPRESSES TO DYSMENORHEA TEENAGE GIRL}

\author{
Mira Astri Koniyo, Rini Fahriani Zees \\ Program Studi Keperawatan \\ Politeknik Kesehatan Gorontalo \\ miraastrikoniyo75@gmail.com
}

\begin{abstract}
Abstrak
Tujuan umum penelitian mengetahui efektifitas pemberian kompres plester hangat dan aroma terapi lavender terhadap penurunan nyeri haid pada remaja Puteri. Desain penelitian ini pra-eksperimen dengan two group pra-post test design dimana peneliti melibatkan dua kelompok remaja Puteri yaitu satu kelompok terapi kompres plester hangat dan satu kelompok terapi kompres plester hangat + aromaterapi lavender. Populasi dalam penelitian ini adalah remaja Puteri yang mengalami dismenorea sebanyak 79, dan Sampel penelitian sebesar 60 sampel. Waktu penelitian dilaksanakan dari tanggal 03 Oktober s.d 14 November 2018. Hasil penelitian berdasarkan uji statistik t-test dependen pada kelompok pertama menunjukkan nilai $\mathrm{p}$ value $0,000<\alpha 0,05$ sehingga $\mathrm{H} 0$ ditolak Ha diterima maka efektif pemberian terapi kompres plester hangat terhadap penurunan nyeri. Pada kelompok kedua berdasarkan uji statistik t-test dependen menunjukkan nilai $\mathrm{p}$ value $0,000<\alpha 0,05$ sehingga $\mathrm{H} 0$ ditolak Ha diterima maka efektif pemberian terapi kompres plester hangat + aromaterapi lavender terhadap penurunan nyeri haid (dismenore).
\end{abstract}

Kata Kunci : Dismenorea, Terapi Plester Hangat, Remaja Puteri

\begin{abstract}
The aim of this study was to observe the effectiveness of giving warm plester compress and lavender aromatherapy toward the decreasing of menstruation on adolescent. The design of this study was pre experiment with two group pra-post test design where the researcher involved two groups of adolescent as well as first group was become compress therapy of warm plester and other group was become compress therapy of warm plester plus lavender aromatherapy. The number of population in this study was adolescent who suffers dysmenorhea as many as 79 respondents and sample of research as many as 60 samples. This study was conducted on 3 october on 2018 until 14 november on 2018. The result of this study based on dependent statistic $t$-test on first group that indicated result $p$ value $0,000<\alpha 0,05$ with Ho is rejected and Ha is accepted that indicated the effectiveness of giving warm plester compress therapy towards decreasing of injuring. The second group is based on dependent statistic t-test on first group that indicated result $p$ value $0,000<\alpha 0,05$ with $\mathrm{Ho}$ is rejected and $\mathrm{Ha}$ is accepted that indicated the effectiveness of giving warm plester compress therapy plus lavender aromatherapy towards decreasing of dysmenorhea
\end{abstract}

Keywords: Dysmenorhea, Warm Plester Compress Therapy, Adolescent 


\section{Pendahuluan}

Perempuan yang mengalami menstruasi mempunyai pengalaman nyeri haid dengan tingkatan yang berbeda. Mulai dari rasa pegal pada bagian panggul dan perut bagian bawah hingga nyeri yang luar biasa sakitnya. Dalam istilah medis rasa sakit atau nyeri dan kram saat haid disebut dengan dysmenorrhea (Sinsin, 2008).

Angka kejadian dysmenorrhea di Indonesia antara 45-95\% di kalangan perempuan usia produktif (Proverawati \& Misaroh, 2009). Sumber lain menyebutkan angka kejadian dysmenorrhea di Indonesia sebesar $64,25 \%$ yang terdiri dari $54,89 \%$ dysmenorrhea primer dan $9,36 \%$ dysmenorrhea sekunder. Seringkali dysmenorrhea primer dialami oleh 60-75\% perempuan muda (Hendrik, 2006).

Dysmenorhea terjadi karena adanya produksi prostaglandin yang berlebihan pada endometrial selama fase luteal. Prostaglandin berdifusi ke dalam endometrial dan menyebabkan kontraksi rahim (Corwin, 2009). Gejala yang muncul saat dysmenorrhea dapat berpengaruh pada aktivitas kerja dan aktivitas sehari- hari (Baradero dkk, 2006). Dysmenorrhea primer mengakibatkan penurunan aktivitas, seperti tidak mengikuti pelajaran di sekolah, tidak mengikuti kegiatan, hanya tiduran, dan sulit berjalan.

Pemberian terapi kompres plester hangat merupakan salah satu tindakan mandiri yang di lakukan oleh tenaga keperawatan. Efek dari kompres plester hangat dapat menyebabkan vasodilatasi pada pembuluh darah yang nantinya akan meningkatkan alirah darah ke jaringan penyaluran zat asam dan makanan ke sel-sel diperbesar dan pembuangan dari zat-zat diperbaiki yang dapat mengurangi rasa nyeri haid primer yang disebabkan suplai darah ke endometrium kurang (Natalia,2013).

Terapi kompres plester hangat terdiri atas beberapa jenis yaitu kompres panas kering dan lembab basah. Kompres panas kering meliputi Bantal panas (buli-buli panas) dan gel pack (Menggunakan jelly). Kompres plester hangat Konvensional mempunyai beberapa kelemahan. Penggunaan air hangat yang digunakan untuk membasahi kain dapat melebar ke bagian-bagian tubuh lain dari klien sehingga menyebabkan ketidaknyamanan. Alasan itulah terapi kompres dengan air hangat dinilai kurang praktis digunakan.

Salah satu aromaterapi yang sering digunakan adalah aromaterapi lavender dimana memiliki komponen utama yaitu lanalol dan linaly asetat yang dapat meningkatkan gelombang-gelombang alfa di dalam otak dan gelombak inilah yang mendorongkan merangkas pengeluaran hormon endorfin sehingga menciptakan keadaan yang rileks atau menenangkan, dapat mengatasi gangguan tidur dan juga depresi (Maifrisco, 2005).

Pada kunjungan kedua yang dilakukan pada tanggal 06 februari 2018 bahwa di SMK Negeri I Limboto, di lakukan wawancara dengan siswi kelas $\mathrm{X}$ bahwa terdapat 79 orang yang mengatakan nyeri saat haid, dan tidak mengetahui cara untuk menghilang nyeri hadi. Tujuan umum mengetahui efektifitas pemberian terapi kompres plester hangat dan aromaterapi terhadap penurunan nyeri haid (dismenorea) pada remaja Puteri kelas X di SMK Negeri I Limboto. Tujuan khusus yaitu, untuk mengidentifikasi terapi kompres plester hangat terhadap penurunan nyeri haid (dysmenorhea) pada remaja kelas X di SMK Negeri I Limboto, untuk mengidentifikasi terapi kompres plester hangat dan aromaterapi lavender terhadap penurunan nyeri haid (dysmenorhea) pada kelas $\mathrm{X}$ di SMK Negeri I Limboto, menganalisis efektifitas terapi kompres plester hangat dan aromaterapi lavender terhadap penurunan nyeri haid (dysmenorhea) di SMK Negeri I Limboto.

\section{Pengertian Dysmenorhea}

Dysmenorhea atau dismenore dalam bahasa Indonesia berarti nyeri pada saat menstruasi (Sukarni \& Wahyu, 2013). Uterus atau rahim terdiri atas otot yang juga berkontraksi dan relaksasi. Pada umumnya, kontraksi otot uterus tidak dirasakan, namun kontraksi yang hebat dan sering menyebabkan aliran darah ke uterus terganggu sehingga timbul rasa nyeri. Ada 
dua tipe dysmenorhea yaitu, dysmenorhea primer dan dysmenorhea sekunder.

Dysmenorhea primer adalah nyeri haid yang dijumpai tanpa kelainan pada alat-alat genetalia yang nyata. Dysmenorhea primer terjadi beberapa waktu setelah Menarche biasanya setelah 12 bulan atau lebih, oleh karena siklus-siklus haid pada bulan-bulan pertama Menarche umumnya berjenis anovulatoar atau bersama-sama dengan permulaan haid dan berlangsung untuk beberapa jam, walaupun pada beberapa kasus dapat berlangsung beberapa hari. Sifat rasa nyeri ialah kejang berjangkitjangkit, biasanya terbatas pada perut bawah, tetapi dapat menyebar kendaerah pinggang dan paha. Bersamaan dengan rasa nyeri dapat dijumpai rasa mual, muntah, sakit kepala, dan sebagainya.

Dysmenorhea sekunder disebabkan oleh kondisi latrogenik dan patologis yang beraksi diuterus, tuba falopi, ovarium, atau pelvis peritonium. Secara umum, nyeri datang ketika terjadi proses yang mengubah mengubah tekanan di dalam atau disekitar pelvis. Perubahan atau terbatasnya aliran darah, atau karena iritasi peritonium pelvis. Proses ini berkombinasi dengan fisiologi normal dari menstruasi sehingga menimbulakn ketidaknyamanan. Ketika gejala ini terjadi pada saat menstruasi, proses ini menjadi sumber rasa nyeri. Penyebab dysmenorhea sekunder dapat di klasifikasikan dua golongan yaitu penyebab intrauterin dan penyebab ekstrauterin (Smith, 2003).

\section{Penyebab Dysmenorhea}

Lapisan sebelah dalam dari kandungan (endometrium) terbentuk dalam persiapan untuk suatu kemungkinan kehamilan. Setelah ovulasi, jika telur tidak dibuahi oleh sebuah sperma, tidak ada kehamilan yang berakibat dan lapisan kandungan sekarang tidak lagi dibutuhkan. Tingkat hormon estrogen dan progesteron seorang perempuan turun, dan lapisan kandungan menjadi membengkak dan mati. Kemudian dilepaskan dan akan diganti dengan suatu lapisan baru pada siklus bulanan berikutnya.

\section{Gejala Dysmenorhea}

Gejala dysmenorhea sering dimulai segera setelah ovulasi dan dapat berlangsung sampai akhir menstruasi. Ini karena dysmenorhea sering dikaitkan dengan perubahan kadar hormon dalam tubuh yang terjadi dengan ovulasi. Penggunaan beberapa jenis pil KB dapat mencegah gejala dysmenorhea karena pil KB berhenti dari terjadi ovulasi. Selama siklus menstruasi perempuan, endometrium menebal dalam persiapan untuk kehamilan potensial. Setelah ovulasi, jika sel telur tidak dibuahi dan tidak ada kehamilan, molekul senyawa yang disebut prostaglandin dilepaskan selama menstruasi, karena penghancuran endometrium, dan pelepasan resultan isinya.

\section{Terapi Dysmenorhea}

Secara umum penanganan dysmenorhea terbagi dalam dua kategori yaitu dengan cara terapi farmakologi dan non farmakologi. Secara farmakologi nyeri dapat ditangani dengan terapi analgesik yang paling umum digunakan untuk menghilangkan nyeri, namun penggunaan analgesik berdampak kepada pengonsumsi karena akan memberikan efek samping obat. Secara non farmakologi meliputi modifikasi gaya hidup, pemenuhan gizi seimbang, kompres hangat dan lembab, Kompres plester hangat, chiropractic, akupuntur, akupresure, hypnosis, homeopaty, penggunaan essens bunga aromaterapi, dan pengobatan herbal (Rosdahl \& Kowalski, 2014).

\section{Pengertian Kompres Hangat}

Kompres hangat adalah suatu metode dalam penggunaan suhu hangat setempat yang dapat menimbulkan beberapa efek fisiologis. Efek terapeutik pemberian kompres plester hangat di antaranya mengurangi nyeri, meningkatkan aliran darah, mengurangi kejang otot, dan menurunkan kekakuan tulang sendi (Mubarak dkk, 2015).

\section{Metode}

Lokasi penelitian yaitu di SMK Negeri I Limboto. Adapun waktu penelitian tanggal 3 Oktober sampai dengan 14 November 2018. Penelitian ini termasuk pra-eksperimen design (rancangan 
praeksperimen) dengan two-group pre-post test design (rancangan pra-pasca tes dalam dua kelompok) yaitu dimana peneliti akan melibatkan dua kelompok remaja puteri yang diobservasi sebelum dilakukan intervensi kompres plester hangat dan kompres plester gel hangat + aroma terapi lavender, kemudian diobservasi lagi setelah dilakukan kedua intervensi tersebut. Penelitian ini tidak menggunakan kelompok kontrol karena keterbatasan waktu dan jumlah remaja puteri yang merasa nyeri saat haid.

Variabel Penelitian Pada penelitian dikenal beberapa jenis variabel berdasarkan hubungan sebab akibat antara lain variabel bebas dan variabel terikat. Variabel independen (variabel bebas) Variabel independen atau variabel bebas dalam penelitian ini adalah terapi kompres plester hangat dan terapi kompres plester hangat + aromaterapi lavender. Variabel Dependen (Variabel terikat), Variabel dependen atau variabel terikat pada penelitian ini adalah tingkat Nyeri Haid Pada Remaja Puteri. Populasi pada penelitian ini yaitu seluruh remaja Puteri kelas $\mathrm{X}$ di SMKN I Kabupaten Gorontalo yang mengalami nyeri haid (dismenorea) berjumlah 79 orang. Teknik pengambilan sampel adalah purposive sampling yaitu peneliti menentukan pengambilan sampel dengan cara menetapkan ciri-ciri khusus yang sesuai dengan tujuan penelitian. Sampel pada penelitian ini adalah siswi SMK Negeri I Limboto Kelas X yang memenuhi kriteria yaitu; siswi yang sedang mengalami menstruasi, siswi yang mengalami dismenorea, bersedia untuk menjadi responden. Jumlah seluruh sampel adalah 60 siswi yang dibagi menjadi 2 kelompok perlakuan. Kelompok pertama berjumlah 30 sampel yang mengalami nyeri haid dilakukan terapi kompres plester hangat dan kelompok kedua berjumlah 30 sampel yang mengalami nyeri haid dilakukan terapi kompres plester hangat + aroma terapi lavender.

\section{Teknik pengumpulan data dan Alur Penelitian}

Pengumpulan data dilakukan dengan mengajukan pertanyaan kepada responden dengan menggunakan lembar kuesioner yang dibuat oleh peneliti tentang umur, waktu Menarche, aktivitas olahraga, riwayat dismenorea dalam keluarga dan skala nyeri sebelum dan setelah dilakukan terapi. Pengisian dilakukan dengan cara memberikan cek list (V) dan dilakukan penskoran dalam bentuk skala likert. Setiap item pertanyaan diberikan nilai. Untuk skala nyeri peneliti membagi dalam 4 kategori yaitu kategori 1 Skala 0 ( tidak nyeri), kategori 2, skala nyeri 1-3 (ringan), Kategori 3, skala nyeri 4-6 (sedang), kategori 7-9 (berat), kategori 4 skala 10 (Berat).

\section{Teknik Analisa Data}

Analisa data merupakan suatu proses yang dilakukan secara sistematis terhadap data yang telah dikumpulkan oleh peneliti. Analisis Univariat Variabel yang dideskripsikan adalah karakteristik remaja puteri meliputi umur, waktu Menarche, lamanya dysmenorhea, aktivitas olahraga yang sering dilakukan, riwayat keluarga yang mengalami dysmenorhea. Analisis Bivariat Dalam kegiatan analisa data, peneliti menggunakan perangkat lunak untuk komputer dengan sistem SPSS (Software Product Service Solution) Versi 16.0 menggunakan Uji paired T-Test. Jika hasil analisa data didapatkan nilai $\mathrm{p}>0,05$ maka $\mathrm{H} 0$ ditolak dan $\mathrm{H} 1$ diterima artinya Efektif Terapi kompres plester hangat dan aromaterapi lavender terhadap Dysmenorhea pada remaja puteri di SMK I Kabupaten Gorontalo.

\section{Hasil Penelitian}

Penelitian ini dilakukan di SMK Negeri I Limboto, Kabupaten Gorontalo pada tanggal 03 Oktober s/d 14 November 2018, dimana sampel penelitian adalah Siswi kelas X di SMK Negeri I Limboto yang mengalami nyeri haid (dysmenorhea) jumlah responden 60 orang. Adapun hasil penelitian yang diperoleh adalah sebagai berikut.

\section{Analisa Univariat, Umur Penderita Dysmenorhea}

Distribusi remaja Puteri menurut usia yang mengalami dismenorea. 
Berdasarkan usia yang mengalami dismenorea, diketahui bahwa dari 60 responden, remaja Puteri yang mengalami dismenorea paling banyak berada pada rentang usia 15-16 tahun yaitu $56(93.33 \%)$

\section{Menarche}

Distribusi Remaja Puteri menurut Kelompok Usia Menarche

Usia remaja Puteri yang mengalami Menarche paling besar berada pada rentang usia 11-13 tahun yaitu 50 (83,33\%).

Efektivitas Kompres Plester Hangat dan Aromaterapi Lavender Terhadap Penurunan Nyeri Haid Pada Remaja Puteri Siswi Kelas X di SMK Negeri I Limboto Kabupaten Gorontalo $(\mathrm{n}=30)$ Berdasarkan Data skala nyeri sebelum dan sesudah dilakukan kompres plester hangat dan pemberian Aromatherapi menujukkan bahwa nilai rata-rata skala nyeri responden sebelum perlakuan 4.90 dengan standar deviasi 1.062. Sedangkan nilai rata-rata skala nyeri responden sesudah perlakuan sebesar 1.40 dengan standar deviasi 0,894. Hasil analisis statistik SPSS dengan mengunakan t-test dependen menunjukkan bahwa hasil $\mathrm{P}$ value adalah 0,000 lebih kecil dari $\alpha=0,05$, sehingga disimpulkan bahwa Ho ditolak dan Ha diterima, sehingga efektif pemberian kompres plester hangat \& Aromatherapy lavender terhadap penurunan dismenore pada remaja Puteri kelas $\mathrm{X}$ di SMK Negeri 1 Limboto.

\section{Pembahasan}

\section{Analisis Univariat}

\section{Karakteristik Responden Berdasarkan umur Penderita Dismenorea}

Berdasarkan karakteristik umur remaja Puteri yang mengalami dismenorea paling banyak adalah pada rentang umur 1516 tahun. Hal ini menunjukkan bahwa dismenore primer dapat dijumpai pada wanita muda yang telah berusia antara usia 15-25 tahun dan akan menghilang pada usia akhir 20-an atau 30-an tanpa ditemukan kelainan alat genital pada pemeriksaan ginekologi. (Yustianingsih 2004). Menurut Proverawati \& Misaroh (2009) dengan bertambahnya umur, nyeri haid akan semakin berkurang dan hilang dengan sendirinya. Hal ini juga didukung oleh Mubarak dkk (2007), yang menyatakan bahwa faktor umur adalah variabel penting yang mempengaruhi respon nyeri.

\section{Karakteristik Responden Berdasarkan Menarche}

Berdasarkan karakteristik umur Menarche pada remaja Puteri paling banyak adalah umur 11 - 13 tahun. Menurut teori yang dikemukakan oleh Sukarni \& Wahyu dimana menstruasi pertama (Menarche) diartikan sebagai permulaan menstruasi pada seorang gadis selama masa pubertas yang biasanya muncul pada usia 11 sampai 14 tahun.

\section{Karakteritik Responden Bedasarkan Frekuensi Olahraga}

Berdasarkan karakteristik responden yang melakukan aktivitas olahraga secara teratur yaitu 2 - 3 kali dalam seminggu, paling banyak responden melakukan frekuensi olahraga 1 kali dalam seminggu. Hal ini didukung oleh penelitian oleh Mahvash dkk (2012) menyatakan terdapat hubungan yang signifikan antara olahraga teratur dengan nyeri dismenorea primer.

\section{Karakteristik Responden Berdasarkan Riwayat Keluarga}

Berdasarkan karakteristik responden yang memiliki riwayat keluarga dismenore lebih besar dibandingkan dengan yang tidak memiliki riwayatkeluarga dismenore. Hal ini sesuai dengan penelitian Andriani (2013), bahwa riwayat keluarga mempunyai peran untuk terjadinya dismenorea primer. Menurut penelitian Ika dan Nunik (2007), menunjukkan bahwa riwayat keluarga atau keturunan mempunyai pengaruh terhadap kejadian dismenore primer. Riwayat keluarga merupakan faktor risiko yang dapat meningkatkan kemungkinan terjadinya dismenore primer. Dua dari tiga wanita yang menderita dismenore primer mempunyai riwayat dismenore primer pada keluarganya.

\section{Analisis Bivariat}

Skala Nyeri Sebelum dan Sesudah Dilakukan kompres plester hangat 


\section{terhadap Penurunan Nyeri Haid (Dysmenorhea)}

Intensitas nyeri sebelum dilakukan terapi kompres plester hangat didapatkan Skala nyeri 3 (ringan) 7 responden, Skala nyeri 4-6 (sedang) 18 responden, skala nyeri 7-8 (berat) 5 responden. Hal ini berasal dari kontraksi rahim yang dirangsang oleh prostaglandin. Nyeri dirasakan semakin hebat ketika bekuan atau potongan jaringan dari lapisan rahim melewati serviks (leher rahim), terutama jika saluran serviksnya sempit. Perbedaan beratnya nyeri saat menstruasi tergantung kepada kadar prostaglandin.Perempuan yang mengalami dysmenorhea atau nyeri menstruasi memiliki kadar prostaglandin yang 5-13 kali lebih tinggi dibandingkan dengan perempuan yang tidak mengalami dysmenorhea (Sukarni \& Wahyu, 2013)

Setelah dilakukan kompres plester hangat terjadi penurunan skala nyeri yaitu skala 0 (tidak nyeri) 7 responden, Skala 1-3 (ringan) 19 responden, skala 4-6 (sedang) 4 responden. Hal ini menunjukkan bahwa terjadi penurunan skala nyeri sebelum dan setelah kompres plester gel hangat.

Keberhasilan terapi kompres plester gel hangat dapat menurunkan dismenore, jika terapi yang dilakukan secara benar dan tepat. Kompres plester ini membuat pembuluh darah bagian tepi pada kulit melebar, pori-pori kulit menjadi terbuka sehingga jaringan sel otot mendapatkan tambahan nutrisi dan oksigen, membantu meningkatkan penyuplaian darah ke kebagian-bagian tubuh dan otot menjadi relaksasi sehingga menyebabkan penurunan nyeri (Nurin dkk, 2017).

\section{Skala Nyeri Sebelum dan Sesudah} Dilakukan Kompres Plester Hangat Dan Aromatherapy Lavender Terhadap Penurunan Nyeri Haid (Dysmenorhea)

Intensitas nyeri sebelum dilakukan terapi kompres plester gel hangat dan aromaterapi lavender didapatkan skala nyeri 3 (ringan) 3 responden, skala nyeri 4-6 (sedang) 25 responden dan skala nyeri 7 (berat) 2 responden. Salah satu faktor timbulnyaTerjadinya dismenorea pada masa remaja, yaitu sekitar 2-3 tahun setelah menstruasi pertama. Salah satu faktor yang menyebabkan dismenorea yaitu faktor psikis dan sosial, karena pada usia remaja pengaruh rekan sebaya mempunyai peranan yang sangat penting yang menjadi asas untuk membuat perbandingan antara tindakan, sikap terutama dalam pencapaian identitas. Apabila pencapaian identitas ini terjadi secara destruktif maka dapat menimbulkan stres. Stres yang berlebihan bisa memicu premenstrual Syndrom yang membuat wanita dismenorea (Abrams, 2017).

Setelah dilakukan terapi kompres plester gel hangat dan aromaterapi lavender terjadi penurunan nyeri haid (dismenorea) yaitu skala 0 (tidak nyeri) 5 responden, skala 1-3 (ringan) 25 responden. Hal ini menunjukkan bahwa kedua terapi ini jika dilakukan secara bersamaan dengan cara yang baik dan benar dapat menurunkan dismenoresecara signifikan. Kompres plester gel hangat menggunakan hidrogel on polyacrylate-basis. Hydrogel mengandung mentol dan paraben, yang keduanya diformulasikan sehingga dapat mempercepat perpindahan panas dari tubuh ke plester kompres ini. Kandungan air yang cukup banyak dalam struktur polimer hidrogel inilah yang berguna untuk menurunkan suhu tubuh dan merelakskan otot-otot. sehingga menyebabkan penurunan nyeri sedangkan Pada aromaterapi lavender terdapat kandungan utamanya yaitu linalyl asetat dan linalool, dimana linalyl asetat berfungsi untuk mengendorkan dan melemaskan sistem kerja saraf dan otot yang mengalami ketegangan sedangkan linalool berperan sebagai relaksasi dan sedatif sehingga dapat menurunkan nyeri haid.

\section{Efektifitas Kompres Plester Hangat Terhadap Penurunan Nyeri Haid Pada Remaja Puteri Kelas $X$ di SMK N I Limboto}

Hasil penelitian menunjukkan bahwa semua responden yang telah diberikan terapi kompres plester hangat mengatakan bahwa terjadi penurunan nyeri haid (dismenorea) hal ini terlihat pada skala tidak nyeri sebanyak 7 orang, nyeri ringan sebebanyak 19 orang, nyeri sedang 4 orang, nyeri berat dan nyeri sangat berat 0 , selain itu 
berdasarkan uji statistik mengunakan t-test dependen menunjukkan bahwa hasil $\mathrm{P}$ value adalah 0,000 lebih kecil dari $\alpha=0,05$, sehingga disimpulkan bahwa Ho ditolak dan Ha diterima, artinya efektif pemberian plester gel hangat terhadap penurunan dismenore pada remaja Puteri kelas $\mathrm{X}$ di SMK Negeri 1 Limboto. kompres plester hangat yang tidak menggunakan air atau alkohol tetapi menggunakan hydrogel on polyacrylate-basis. Hydrogel ini telah menjadi bahan pembuatan plester kompres yang banyak digunakan di Indonesia. Hidrogel ini merupakan salah satu polimer yang mempunyai ikatan silang atau crosslink yang didalamnya terkandung air dalam jumlah cukup banyak yaitu sekitar lebih dari tujuh puluh persen.

Hydrogel juga mengandung mentol dan paraben, yang keduanya diformulasikan sehingga dapat mempercepat perpindahan panas dari tubuh ke plester kompres ini. Paraben sendiri merupakan senyawa berbentuk serbuk kristal putih yang tidak dapat larut kedalam air, namun mudah larut kedalam methanol dan enthanol yang mempunyai sifat antibakteri. Kandungan air yang cukup banyak dalam struktur polimer hidrogel inilah yang berguna untuk menurunkan suhu tubuh dan merelakskan otot- otot.

Cara kerja dari kompres plester ini membuat pembuluh darah bagian tepi pada kulit melebar, pori-pori kulit menjadi terbuka sehingga jaringan sel otot mendapatkan tambahan nutrisi dan oksigen, membantu meningkatkan penyuplaian darah ke kebagian-bagian tubuh dan otot menjadi relaksasi sehingga menyebabkan penurunan nyeri. Menurut Natalia, 2013 efek dari kompres plester hangat dapat menyebabkan vasodilatasi pada pembuluh darah yang nantinya akan meningkatkan alirah darah ke jaringan penyaluran zat asam dan makanan ke sel-sel diperbesar dan pembuangan dari zat-zat diperbaiki yang dapat mengurangi rasa nyeri haid primer yang disebabkan suplai darah ke endometrium kurang (Natalia, 2013). Hal ini didukung oleh hasil penelitian Eka Rahmidiyanti dkk, 2017 Hasil penelitian menunjukkan bahwa ratarata skor derajat nyeri haid Hasil uji wilcoxon nilai $\mathrm{p}$ menunjukkan bahwa ada hubungan yang bermakna antara kompres hangat dengan penurunan derajat nyeri haid $(\mathrm{p}=0,0001)$.

\section{Efektifitas Kompres Plester Hangat Dan Aromaterapi Lavender Terhadap Penurunan Nyeri Haid Pada Remaja Puteri Kelas X di SMK N I Limboto}

Terapi kompres plester hangat dan aromaterapi lavender semua responden mengatakan terjadi penurunan nyeri haid (dismenore) yang dapat terlihat hasil penelitian menunjukkan tidak nyeri sebanyak 5 orang, nyeri ringan sebebanyak 25 orang. selain itu berdasarkan hasil uji statistik SPSS mengunakan t-test dependen menunjukkan bahwa hasil $\mathrm{P}$ value adalah 0,000 lebih kecil dari $\alpha=0,05$, sehingga disimpulkan bahwa Ho ditolak dan $\mathrm{Ha}$ diterima, sehingga efektif pemberian kompres plester gel hangat dan aromaterapi lavender terhadap penurunan dismenore pada remaja Puteri kelas X di SMK Negeri 1 Limboto.

Aromaterapi lavender memiliki komponen utama yaitu lanalol dan linaly asetat yang dapat meningkatkan gelombanggelombang alfa di dalam otak dan gelombak inilah yang mendorongkan merangkas pengeluaran hormone endorphin sehingga menciptakan keadaan yang rileks atau menenangkan, dapat mengatasi gangguan tidur dan juga depresi, minyak esensial lavender bisa memicu alergi bahkan bisa menjadi racun jika pasien mempunyai riwayat alergi terhadap bunga lavender (Maifrisco, 2005). hal ini didukung oleh hasil penelitian Rica Pustikawaty, 2016 sebelum dilakukan aromaterapi lavender didapatkan skala nyeri terbanyak pada responden yaitu skala nyeri sedang $68,8 \%$. Setelah dilakukan aromaterapi lavender didapatkan skala nyeri terbanyak pada responden yaitu skala nyeri ringan $75 \%$ Pada uji t- tes paired didapatkan hasil bahwa nilai $\mathrm{p}=0,000$ sehingga Terdapat pengaruh aromaterapi lavender terhadap penurunan skala nyeri haid siswi kelas X Sekolah Menengah Atas Negeri 1 Sungai Ambawang Penelitian lainnya oleh penelitian Yuni fazriah, 2015 disimpulkan bahwa terdapat pengaruh yang signifikan pemberian massage effuearage 
menggunakan aromaterapi lavender terhadap penurunan nyeri disminorea.

\section{Aktivitas Olahraga Pada Remaja Puteri Kelas X Mengalami Dismenorea}

Dari hasil penelitian ini terdapat hubungan antara olahraga yang tidak teratur pada remaja Puteri kelas $\mathrm{X}$ terhadap terjadinya dismenorea. Hal ini ditunjukkan bahwa terdapat 50 remaja Puteri yang mengalami dismenorea hanya melakukan olahraga 1 kali dalam seminggu yang termasuk pada aktivitas olahraga tidak teratur dan 10 remaja Puteri yang mengalami dismenorea melakukan olahraga 2 kali seminggu yang termasuk dalam kategori olahraga teratur. Berdasarkan hal tersebut menunjukkan bahwa remaja Puteri yang tidak teratur melakukan olahraga mempunyai resiko lebih besar mengalami dismenorea.

\section{Riwayat Keluarga Pada Remaja Puteri Kelas X Mengalami Dismenorea}

Dari hasil penelitian terdapat hubungan antara remaja Puteri yang memiliki riwayat keluarga dismenorea baik pada ibunya, tante dan saudara lainnya terhadap terjadinya dismenorea. Hal ini ditunjukkan bahwa terdapat 31 (51,66\%) remaja Puteri kelas $\mathrm{X}$ yang mengalami dismenorea terdapat riwayat keluarga dismenorea. Menurut Colema, (1991), riwayat keluarga merupakan faktor risiko yang dapat meningkatkan terjadinya dismenorea primer. Berdasarkan hal tersebut bahwa remaja Puteri kelas $\mathrm{X}$ yang memiliki riwayat keluarga dismenorea mempunyai resiko lebih besar terjadinya dismenorea dibandingkan yang tidak memiliki riwayat keluarga.

\section{Efektif Kompres Plester Hangat Dan Aromaterapi Lavender Terhadap Penurunan Skala Nyeri.}

Kompres plester hangat efektif terhadap penurunan nyeri. Hal ini dibuktikan setelah dilakukan terapi nilai rata-rata 1,90 dengan standar deviasi 0.607 dan uji statistik t_test hasil $\mathrm{P}$ value 0,000. Sedangkan untuk terapi kompres plester hangat dan aromaterapi lavender pada nilai rata-rata setelah dilakukan dua perlakuan didapatkan 1.40 dengan standar deviasi
0.894 dan uji t_test paired hasil $\mathrm{P}$ value 0,000. Hal ini menunjukkan bahwa efektif terapi kompres plester hangat dan aromaterapi lavender terhadap penurunan nyeri pada remaja Puteri kelas X di SMK N I Limboto.

\section{Kesimpulan}

Berdasarkan hasil penelitian yang dilakukan terhadap 60 responden yang dikelompokkan menjadi dua kelompok yaitu kelompok pertama dilakukan terapi kompres plester hangat pada 30 responden dan kelompok kedua dilakukan terapi kompres plester hangat dan aromaterapi lavender pada 30 responden maka peneliti menemukan kesimpulan sebagai berikut:

1. Sebelum dilakukan terapi kompres plester hangat ditemukan skal nyeri 1-3 (ringan) 7 responden, skala 4-6 (sedang) 18 responden, skala 7-9 (berat) 5 responden. Setelah dilakukan terapi terjadi penurunan skala nyeri yaitu skala 0 (tidak nyeri) 7 responden, Skala 1-3 (ringan) 19 responden, skala 4-6 (sedang) 4 responden. Hal ini menunjukkan bahwa terjadi penurunan skala nyeri setelah dilakukan terapi kompres plester hangat.

2. Sebelum dilakukan terapi kompres plester hangat dan aromaterapi lavender ditemukan skala 1-3 (ringan) 3 responden, skala 4-6 (sedang) 25 responden, skala 7-9 (berat) 2. Setelah dilakukan terapi terjadi penurunan nyeri haid (dismenorea) yaitu skala 0 (tidak nyeri) 5 responden, skala 1-3 (ringan) 25 responden. Hal ini menunjukkan bahwa terjadi penurunan skala nyeri setelah dilakukan terapi kompres plester hangat dan aromaterapi lavender.

3. Terapi kompres plester hangat berdasarkan uji statistik mengunakan ttest dependen menunjukkan bahwa hasil $\mathrm{P}$ value adalah 0,000 lebih kecil dari $\alpha=$ 0,05, sehingga disimpulkan bahwa Ho ditolak dan Ha diterima, artinya efektif pemberian plester hangat terhadap penurunan dismenore pada remaja Puteri kelas X di SMK Negeri 1 Limboto.

4. Terapi kompres plester hangat + aromaterapi lavender berdasarkan hasil uji statistik t-test dependen menunjukkan bahwa hasil $\mathrm{P}$ value adalah 0,000 lebih 
kecil dari $\alpha=0,05$, sehingga disimpulkan bahwa Ho ditolak dan $\mathrm{Ha}$ diterima, sehingga efektif pemberian kompres plester hangat dan aromaterapi lavender terhadap penurunan dismenore pada remaja Puteri kelas X di SMK Negeri 1 Limboto.

\section{Saran}

1. Petugas UKS dapat melakukan terapi kompres plester hangat dan aromaterapi ini kapan saja di UKS jika terdapat siswi mengalami nyeri haid (dismenorea).

2. Pemberian terapi kompres plester hangat dan aroma terapi ini sangat mudah dilakukan dan praktis sehingga remaja Puteri yang mengalami dismenorea dapat melakukan walaupun saat proses belajar berlangsung dikelas, ataupun dimana saja berada tanpa membatasi aktivitas.

3. Bagi peneliti selanjutnya agar dapat melakukan penelitianlebih lanjut tentang terapi kompres plester hangat dan aromaterapi dengan desain penelitian yang lainserta melakukan penelitian tentang tindakan yang lainnya untuk menurunkan nyeri haid (dismenorea)

\section{Daftar Pustaka}

Baradero, M. dkk. (2006). Prinsip dan Praktek Keperawatan Perioperatif. Penerbit Buku Kedokteran EGC: Jakarta

Corwin, E. J.2009). Buku Saku Patofisiologi. Aditya Media: Jakarta

Hendrik. 2006. Problema Haid: Tinjauan Syariat Islam dan Medis. PT Tiga. Serangkai: Solo

Maifrisco. 2008. Pengaruh Aromaterapi Terhadap Stress Mahasiswa. Duinduh di URL: www.indoskripsi.com

Mubarak, I.W, dkk. 2007. Ilmu Keperawatan Komunitas Konsep dan Aplikasi. Jakarta: Salemba Medika

Mubarak, I.W, dkk. 2015. Buku Ajar Ilmu Keperawatan Dasar (Buku 1). Salemba Medika: Jakarta.

Mahvash, dkk. 2012. The Effect of Physical on Primary Dysmenorrheal of Female University Student. World Applied Sciences Journal 17(10): 12461252,1012
Proverawati \& Misaroh. 2009. Menarche Menstruasi Pertama Penuh. Makna. Nuha Medika: Yogyakarta

Rosdahl. C. B \& Kowalski. M. T (2014). Buku ajar keperawatan dasar. Volume 1. Edisi 1. EGC.: Jakarta

Sinsin, I. 2008. Seri Kesehatan Ibu dan Anak Masa Kehamilan dan Persalinan. Alex Media: Jakarta

Smith, R.P. 2003. Dysmenorrhea: Etiology, Diagnosis, and Therapy. Diakses dari http://www.omenshealthapta.org

Sukarni \& Wahyu, 2013, Buku Ajar Keperawatan Maternita. Nuha Medika: Yogyakarta

Yustianingsih, A. 2004. Hubungan Aktifitas Olahraga terhadap Disminorea pada Siswi SMK Pemuda Muhammadiyah Krian Sidoarjo Jawa Timur. UGM: Yogyakarta 